\title{
UBIQUITOUS COMPUTING AND SCRUM SOFTWARE ANALYSIS For COMMUNITY SOFTWARE
}

\author{
Atif Bilal $^{1}$, Zubair Nabi $^{2}$, Muhammad Awais ${ }^{3}$ Muhammad Yahya Saeed ${ }^{4}$ and \\ Maliha Chaudhary ${ }^{5}$ \\ 1,2,3,4 Department of Software Engineering, Government College University, Faisalabad, \\ ${ }^{5}$ University of Agriculture, Faisalabad.
}

\begin{abstract}
Ubiquitous processing has the special property when contrasted with customary desktop figuring framework. Really in ubiquitous, more computational force in the earth by utilizing any gadget everything was accessible and open. Numerous machines give the interface to the single client by concealing every one of the gadgets from the foundation. Programming Engineering has unbelievable meaning in the area of pervasive processing. There was no basic level engineering which was utilized and satisfactory for a wide range of ubiquitous figuring application. Because of less programming designing methodologies were distinguished, this was fundamental issue in the root to propose general level engineering. To reach on this objective, step was taken at exceptionally introductory level to seek out all the believable programming designing difficulties in numerous ubiquitous registering applications that were at that point grew as such. Attempt to highlight all methodologies that ever been utilized to built up the universal applications. This exploration is extremely useful in future for analysts to construct the general level engineering for the ubiquitous applications
\end{abstract}

\section{KEYWORDS}

Ubiquitous, methodologies, engineering

\section{INTRODUCTION}

\subsection{Review of Literature}

Whang et al. (2007) Proposes the utilization of a system for the acceptance of AmI based UbiCom applications. This philosophy depends on the utilization and advancement of MultiAgent Based Simulations (MABS). The proposition is roused by AmI based UbiCom applications which include huge quantities of clients or perilous situations. Consequently, these applications are not suitable to be accepted with genuine tests. The investigation of the related works reasons that the acceptance of UbiCom System through genuine tests and the past re-enactments approaches can't manage applications where there are a huge number of clients. This paper means to exhibit that MABS is a perfect innovation for the acceptance of UbiCom plans before their sending. Also, the study has finished up there is an inborn inconvenience in the examination of MABS which can be helped with innovations, for example, information mining or informal organization examination. Criminological examination is proposed as a backing for these innovations to help MABS investigation. The primary commitment exhibited is a strategy to create MABS so as to accept AmI based UbiCom applications [1].

Mutahdi et al. (2010) introduced a context-aware access control mechanism that utilizes threshold cryptography and multilayer encryption to provide a dynamic and truly distributed method for access control. We simulate our access control scheme and show that access control decisions can

DOI : $10.5121 /$ ijsea.2016.7608 
International Journal of Software Engineering \& Applications (IJSEA), Vol.7, No.6, November 2016

be made in a timely manner even as we increase key and file sizes. This mechanism is closely coupled with the context-capturing services and security policy service resulting in a fully context-aware and seamless access control mechanism for typical ubiquitous computing scenarios. In addition, trust is distributed throughout the ubiquitous computing infrastructure. We believe that contextual awareness can enrich traditional security mechanisms with greater flexibility and expressiveness power and enable a variety of security services [2].

Serrano et al. (2010) introduced a new methodology based on the use of Multi-Agent Based Simulations (MABS) for testing and validation of Ambient Intelligence based Ubiquitous Computing (UbiCom) systems. An ambient intelligence based UbiCom is a pervasive system in which services have some intelligence in order to smoothly interact with users immersed in the environment. The motivation for this methodology is its application in UbiCom large-scale systems where large numbers of users are involved and in applications which deal with dangerous environments. This paper also proposes two techniques for the analysis of general complex MABSs: forensic analysis and the use of simpler simulations [3].

Kim et al. (2010) derived the security requirements of a child-care and safety service and establish a conceptual model satisfying the requirements. Based on the system model, we propose a privacy-preserving location supporting protocol for a child-care and safety service using wireless sensor networks. While addressing the above problems, our protocol can be operated over various networks (e.g., Wi-Fi and UWB) providing an RSSI (received signal strength indication) without any modification. Through performance and security analysis of our protocol, we show that our protocol is efficient and secure [4].

Emilio et al (2010) presents another philosophy in view of the utilization of Multi-Agent Based Simulations (MABS) for testing and approval of Ambient Intelligence based Ubiquitous Computing (UbiCom) frameworks. A surrounding insight based UbiCom is a pervasive framework in which benefits have some knowledge so as to easily collaborate with clients submerged in the earth. The inspiration for this philosophy is its application in UbiCom extensive scale frameworks where vast quantities of clients are included and in applications which manage risky situations. This paper additionally proposes two procedures for the investigation of general complex MABSs: legal examination and the utilization of easier recreations. Additionally, the procedure proposes to infuse components of the genuine UbiCom framework in the recreated world to expand the certainty of the acceptance process. The proposition is delineated with a nitty gritty contextual analysis that considers an expanding on our grounds and an AmI administration for clearing if there should be an occurrence of flam [5].

Ville (2011) portrays transaction and battle over the importance of security in the setting of the proposed rise of "omnipresent registering society" which alludes to a dream of a general public where PC innovation, as modest microchips and remote systems, has been flawlessly coordinated into regular items and exercises. As a delineation of the re-arrangement of the idea of "security" that develops with "pervasiveness", the news scope of the 2011 Apple area following embarrassment was investigated from a talk scientific point of view. Utilizing the idea of an interceded outrage, the explanation of security was examined in connection to the media as the site for the social arrangement concerning protection. Two contending talks concerning protection were distinguished. In the social talk, protection was comprehended as debatable in the changing conditions that innovative advancement produces. In a principal talk, mechanical advancement was explained in relationship to the major and general right to security. The study recommends two contrasting understandings of how security would be re-arranged in this procedure of progress as omnipresent figuring society develops [6]. 
International Journal of Software Engineering \& Applications (IJSEA), Vol.7, No.6, November 2016

Hallsteinsen et al.(2012) presents the MUSIC venture has given a cognizant arrangement of arrangements which facilitate the undertaking of creating setting mindful, self-adaptive frameworks for versatile and universal registering situations. While the vast majority of the different viewpoints and bits of building self-adaptive frameworks have been tended to before in other exploration ventures, MUSIC emerges on the grounds that it has taken a gander at the complete picture and has conveyed an exhaustive and reasonable advancement structure, philosophy, and execution stage. The aftereffects of MUSIC have been received as of now by follow-on undertakings, and we expect that the improvement of self-versatile applications and comparing systems will develop in various headings later on. Extending the MUSIC system for smart interactive media content adjustment is one testing research back road, while different endeavours will look to guarantee that the adjustments are as tried and true as could be allowed to bring autonomic registering to operation basic applications. The present form of the MUSIC middleware offers just essential backing for security in light of the fact that extend deliberately cantered on the depicted adjustment angles [7].

Aysegul et al.(2013) addressed the achievement of the setup choices is very important. Keeping in mind the end goal to meet the difficulties of the issue, we proposed a methodology in view of machine realizing so that the conduct of the information mining calculation in differing circumstances is demonstrated to be utilized for the setup of the calculation. In our approach, the acknowledged information mining quality is a piece of the conduct demonstrate so that whether the arrangement quality objectives are achieved or not is surveyed. In particular, adjusting to the changing conditions by creating another conduct model of information mining is conceivable at whatever point the current conduct model needs in accomplishing the design quality objectives [8].

Ezequiel et al.(2015) Proposed Scrum in under graduate programming building courses is a compelling approach to update and increase the value of professional preparing. In this paper, we have certified that the understudies' information of Scrum was enhanced when understudies were given suit-capable instructional techniques as indicated by the preparing measurement of the understudies 'learning styles. The investigations were completed with regards to an undergrad programming designing course and have given confirmation to bolster the lattice speculation. Particularly, the tests have uncovered that understudies who were given learning opportunities in accordance with their learning 'inclinations accomplished better instructive results [9].

Florin et al (2015) portrays the late extension of Cloud Systems has prompted adjusting asset administration answers for expansive number of wide conveyed and heterogeneous data centres. This unique issue presents progresses in virtual machine task and situation, multi-objective and multi-requirements work booking, asset administration in unified Clouds and in heterogeneous situations, dynamic topology for information circulation, work process execution change, vitality effectiveness procedures and confirmation of Service Level Agreements [10].

\subsection{Materials and Methods}

Universal processing has the one of a kind property when contrasted with customary desktop registering framework. Really in ubiquitous, more computational force in the earth by utilizing any gadget everything was accessible and open. Numerous machines give the interface to the single client by concealing every one of the gadgets from the foundation. Programming Engineering has unbelievable meaning in the area of pervasive processing. There was no normal level design which was utilized and satisfactory for a wide range of ubiquitous figuring application. Because of less programming designing methodologies were distinguished, this was fundamental issue in the root to propose general level engineering. To reach on this objective, stride was taken at extremely starting level to look out all the possible programming building 
International Journal of Software Engineering \& Applications (IJSEA), Vol.7, No.6, November 2016 challenges in numerous ubiquitous registering applications that were at that point grew in this way. Attempt to highlight all methodologies that ever been utilized to built up the universal applications. This exploration is extremely useful in future for analysts to assemble the general level engineering for the common applications.

Here we compared these all technologies with different perspectives.

Table 1: Necessary technologies for ubiquitous computing.

\begin{tabular}{|l|l|l|l|l|l|l|}
\hline & Mobility & Embeddedness & $\begin{array}{c}\text { Ad hoc } \\
\text { networks }\end{array}$ & $\begin{array}{c}\text { Context } \\
\text { awareness }\end{array}$ & $\begin{array}{c}\text { Energy } \\
\text { autarky }\end{array}$ & Autonomy \\
\hline Microelectronics & $\sqrt{ }$ & $\sqrt{ }$ & & & & \\
\hline Power supply & $\sqrt{ }$ & & $\sqrt{ }$ & & $\sqrt{ }$ & $\sqrt{ }$ \\
\hline Sensor technology & & & $\sqrt{ }$ & $\sqrt{ }$ & & $\sqrt{ }$ \\
\hline $\begin{array}{l}\text { Communication } \\
\text { technology }\end{array}$ & $\sqrt{ }$ & & $\sqrt{ }$ & $\sqrt{ }$ & & $\sqrt{ }$ \\
\hline $\begin{array}{l}\text { Localization } \\
\text { technology }\end{array}$ & $\sqrt{ }$ & & & $\sqrt{ }$ & & $\sqrt{ }$ \\
\hline $\begin{array}{l}\text { Security } \\
\text { technology }\end{array}$ & & $\sqrt{ }$ & $\sqrt{ }$ & $\sqrt{ }$ & & \\
\hline $\begin{array}{l}\text { Machine- } \\
\text { to-machine } \\
\text { communication }\end{array}$ & & $\sqrt{ }$ & $\sqrt{ }$ & $\sqrt{ }$ & & $\sqrt{ }$ \\
\hline $\begin{array}{l}\text { Human-machine } \\
\text { interface }\end{array}$ & & $\sqrt{ }$ & & $\sqrt{ }$ & & $\sqrt{ }$ \\
\hline
\end{tabular}

\section{Contrast Between Attributes Of Tools Or Products}

Here the contrast of attributes of different technologies is defined:

\section{Mobility}

\begin{tabular}{|l|l|}
\hline Microelectronics & Power Supply \\
\hline $\begin{array}{l}\text { Microelectronics manages the scaling } \\
\text { down, improvement, production and } \\
\text { utilization of in time circuits. They have } \\
\text { small size and can be moved easily } \\
\text { from one place to another. }\end{array}$ & $\begin{array}{l}\text { Supplying energy to electronic } \\
\text { frameworks is fundamental condition for } \\
\text { utilizing universal registering } \\
\text { applications. In this way, advance in chip } \\
\text { innovations and hardware improvement } \\
\text { has reliably expanded portability. }\end{array}$ \\
\hline $\begin{array}{l}\text { Sensor Technology } \\
\begin{array}{l}\text { Sensor is used as an electronic } \\
\text { component is ubiquitous computing. It } \\
\text { is tiny device. The devices in which }\end{array}\end{array}$ & $\begin{array}{l}\text { The innovation and business sector } \\
\text { patterns specialists perceive } \\
\text { correspondence innovation as a key driver }\end{array}$ \\
\hline
\end{tabular}


International Journal of Software Engineering \& Applications (IJSEA), Vol.7, No.6, November 2016

\begin{tabular}{|c|c|}
\hline $\begin{array}{l}\text { sensor is used have also small size these } \\
\text { are easy to move from one place to } \\
\text { another. }\end{array}$ & $\begin{array}{l}\text { for ubiquitous processing. This } \\
\text { technology has increased mobility } \\
\text { capability and easy to change and move. }\end{array}$ \\
\hline $\begin{array}{l}\text { Sensor is used as an electronic } \\
\text { component is ubiquitous computing. It } \\
\text { is tiny device. The devices in which } \\
\text { sensor is used have also small size these } \\
\text { are easy to move from one place to } \\
\text { another. }\end{array}$ & $\begin{array}{l}\text { The innovation and business sector } \\
\text { patterns specialists perceive } \\
\text { correspondence innovation as a key driver } \\
\text { for ubiquitous processing. This } \\
\text { technology has increased mobility } \\
\text { capability and easy to change and move. }\end{array}$ \\
\hline Localization Technology & Security Technology \\
\hline $\begin{array}{l}\text { One attractive feature of ubiquitous } \\
\text { registering is that outfitting brilliant } \\
\text { articles with suitable transmitters and } \\
\text { recipients empowers exact confinement. } \\
\text { This technology has increased mobility } \\
\text { capability. }\end{array}$ & $\begin{array}{l}\text { A important element of ubiquitous } \\
\text { registering is that almost all confidence } \\
\text { articles can trade data. Security is in this } \\
\text { way key in ubiquitous figuring. This is } \\
\text { generally performed utilizing remote } \\
\text { devises. }\end{array}$ \\
\hline Machine to Machine Communication & Human Machine Interface \\
\hline $\begin{array}{l}\text { Ubiquitous registering frameworks will } \\
\text { be exceptionally appropriated } \\
\text { frameworks with thousands or a huge } \\
\text { number of suddenly cooperating } \\
\text { segments. These parts are of grin size } \\
\text { and solid. }\end{array}$ & $\begin{array}{l}\text { The sharp objects of pervasive figuring } \\
\text { require engineers who outline UIs that } \\
\text { move past the some time ago crushing } \\
\text { screen/console rule. This technology has } \\
\text { the great mobility feature. }\end{array}$ \\
\hline
\end{tabular}

\section{Embeddedness}

\begin{tabular}{|c|c|}
\hline Micro-electronics & Power Supply \\
\hline $\begin{array}{l}\text { All in all, microelectronics is a full } \\
\text { grown and broadly accessible } \\
\text { innovation and does not represent any } \\
\text { bottlenecks for ubiquitous registering. } \\
\text { The gadgets in this innovation are } \\
\text { inserted and can be utilized as a part of } \\
\text { numerous bearings. }\end{array}$ & $\begin{array}{l}\text { Indeed, even along these lines, for most } \\
\text { applications the force supply is the } \\
\text { biggest and heaviest segment, and the } \\
\text { greatest limitation on use. But we can } \\
\text { embed the devices in it and can use them } \\
\text { in different ways and in different } \\
\text { directions. }\end{array}$ \\
\hline Sensor Technology & Communication Technology \\
\hline $\begin{array}{l}\text { The key elements of sensor } \\
\text { improvement today incorporate } \\
\text { lessened the size and weight of sensors } \\
\text { and sensor frameworks, coordination of } \\
\text { the sensors into complex semiconductor } \\
\text { frameworks, diminishing, } \\
\text { embeddedness and force. }\end{array}$ & $\begin{array}{l}\text { In this technology different technologies } \\
\text { are embedded and used in different ways } \\
\text { like satellite technology, telephony, radio } \\
\text { engineering, communication engineering } \\
\text { and switching technology. }\end{array}$ \\
\hline Localization Technology & Security Technology \\
\hline
\end{tabular}


International Journal of Software Engineering \& Applications (IJSEA), Vol.7, No.6, November 2016

There are at present three sorts of limitation frameworks: satellite-upheld, cell bolstered and indoor confinement frameworks. These are merged or embedded with other devices for better work and understanding. It leads to powerful working of technology.

Machine to Machine Communication

Different standards are used in this technology. Standardization is very important. In different standards different devices are connected to each other and are embedded in different ways to get great performance. Embeddedness is very important in this technology.
In security technology different devices are used and are embedded to get the high security, and to make the security more powerful and safe. By using different powerful devices we can save the data from unauthorized access. And can use it safely.

Human Machine Interface

Innovation specialists trust that humanmachine interfaces will assume a fairly normal part for the advancement of pervasive registering.

Different devices are merged in this technology and have the great embeddedness power.

\section{Ad Hoc Networks}

\begin{tabular}{|l|l|}
\hline Microelectronics & Power Supply \\
\hline $\begin{array}{l}\text { Microelectronics can be used as ad-hoc } \\
\text { network we can connect many devices } \\
\text { for different type of communication and } \\
\text { we can connect the different number of } \\
\text { devices. This technology gives us the } \\
\text { benefit of small networking. }\end{array}$ & $\begin{array}{l}\text { Power supply have the capability of ad- } \\
\text { hoc network we can connect many } \\
\text { devices for different type of } \\
\text { different number of devices. This } \\
\text { technology gives us the benefit of small } \\
\text { networking. }\end{array}$ \\
\hline $\begin{array}{l}\text { Sensor Technology } \\
\text { Communication Technology }\end{array}$ \\
\hline $\begin{array}{l}\text { Sensor Technology is the most powerful } \\
\text { technology today. It can be used in } \\
\text { every field. It can be used with ad-hoc } \\
\text { networks. And it can play the role of ad- } \\
\text { hoc networks by connecting different } \\
\text { devices. }\end{array}$ & $\begin{array}{l}\text { Communication technology has the base } \\
\text { of networking. In this technology } \\
\text { different networking standards are used } \\
\text { and this technology can be used as ad-hoc } \\
\text { networking by connecting and merging } \\
\text { different devices. }\end{array}$ \\
\hline $\begin{array}{l}\text { Localization Technology } \\
\text { Numerous innovation specialists feel } \\
\text { that limitation innovation is the slightest } \\
\text { applicable for universal registering } \\
\text { among every one of the fields. But it } \\
\text { can be used with ad-hoc networks very } \\
\text { efficiently and can also work as small } \\
\text { self- made networks. These networks } \\
\text { are made for small use. }\end{array}$ & $\begin{array}{l}\text { When in disbelief, it is difficult to create } \\
\text { frameworks with high happiness levels in } \\
\text { ubiquitous figuring because of the high } \\
\text { multifaceted nature and systems } \\
\text { administration of huge number of } \\
\text { dissimilar units. But by using this } \\
\text { technology we can make our networks } \\
\text { secure. }\end{array}$ \\
\hline $\begin{array}{l}\text { Machine to Machine Communication } \\
\text { Human Machine Interface }\end{array}$ \\
\hline
\end{tabular}


International Journal of Software Engineering \& Applications (IJSEA), Vol.7, No.6, November 2016 As the systems administration of keen Human machine interface is the most articles turns out to be progressively mind boggling, the potential for threat likewise rises pointedly. It is no more possible to expressly program all collaborations among the items, on the grounds that there are just extremely numerous believable blends.

\section{Context Awareness}

\begin{tabular}{|c|c|}
\hline Microelectronics & Power Supply \\
\hline $\begin{array}{l}\text { Context-aware systems are a component } \\
\text { of pervasive computing environment or } \\
\text { ubiquitous computing. Microelectronics } \\
\text { also used the technology of context } \\
\text { awareness. It has the capability of } \\
\text { context aware systems. }\end{array}$ & $\begin{array}{l}\text { Flexible and remote frameworks with } \\
\text { force independence have gotten to be } \\
\text { imperative as of late. The power supply } \\
\text { technology has also used the technology } \\
\text { of context awareness. It has the capability } \\
\text { of context aware systems. }\end{array}$ \\
\hline Sensor Technology & Communication Technology \\
\hline $\begin{array}{l}\text { Portable and isolated frameworks with } \\
\text { force freedom have gotten to be critical } \\
\text { just now For getting this purpose } \\
\text { Context awareness is very important. } \\
\text { This technology is used in sensor } \\
\text { devices and these devices make the } \\
\text { better use of this technology. }\end{array}$ & $\begin{array}{l}\text { Communication novelty is for the most } \\
\text { part consolidated with data novelty and } \\
\text { alluded to all things considered as the } \\
\text { ICT to highlight the cover between the } \\
\text { two fields. These two fields are combined } \\
\text { and used with context awareness } \\
\text { technology for better performance. }\end{array}$ \\
\hline Localization Technology & Security Technology \\
\hline $\begin{array}{l}\text { One exciting certainty of universal } \\
\text { registering is that outfitting sharp items } \\
\text { with suitable transmitters and collectors } \\
\text { empowers exact confinement. } \\
\text { Localization technology also use the } \\
\text { Context awareness technology for better } \\
\text { communication and results. }\end{array}$ & $\begin{array}{l}\text { The basic targets of a security system are } \\
\text { to guarantee classification, uprightness, } \\
\text { non-disavowal, accessibility, } \\
\text { namelessness and substance. For getting } \\
\text { this goal in an efficient and secure way } \\
\text { context awareness technology is used. }\end{array}$ \\
\hline Machine to Machine communication & Human Machine Interface \\
\hline $\begin{array}{l}\text { The institutionalization of proper } \\
\text { machine-machine interfaces and their } \\
\text { advancement are along these lines } \\
\text { uncommonly vital for pervasive } \\
\text { registering. Context awareness } \\
\text { technology is used in this } \\
\text { communication for better results. }\end{array}$ & $\begin{array}{l}\text { The shining objects of universal figuring } \\
\text { require engineers who plan UIs that move } \\
\text { past the earlier overpowering } \\
\text { screen/console standard. Context } \\
\text { awareness technology is used for getting } \\
\text { it. }\end{array}$ \\
\hline
\end{tabular}

\section{Autonomy}

\begin{tabular}{|l|l|}
\hline Microelectronics & Power Supply \\
\hline
\end{tabular}


International Journal of Software Engineering \& Applications (IJSEA), Vol.7, No.6, November 2016

\begin{tabular}{|c|c|}
\hline $\begin{array}{l}\text { Context-aware systems are a component } \\
\text { of pervasive computing environment or } \\
\text { ubiquitous computing. Microelectronics } \\
\text { also used the technology of context } \\
\text { awareness. It has the capability of } \\
\text { context aware systems. }\end{array}$ & $\begin{array}{l}\text { Portable and remote frameworks with } \\
\text { force independence have gotten to be } \\
\text { vital as of late. The power supply } \\
\text { technology has also used the technology } \\
\text { of context awareness. It has the capability } \\
\text { of context aware systems. }\end{array}$ \\
\hline Sensor Technology & Communication Technology \\
\hline $\begin{array}{l}\text { Catching and contravention down this } \\
\text { present reality is one of the focal } \\
\text { attributes of ubiquitous processing. For } \\
\text { getting this purpose Context awareness } \\
\text { is very important. This technology is } \\
\text { used in sensor devices and these devices } \\
\text { make the better use of this technology. }\end{array}$ & $\begin{array}{l}\text { Communication innovation is for the } \\
\text { most part consolidated with data } \\
\text { innovation and alluded to by and large as } \\
\text { the ICT so as to stress the cover between } \\
\text { the two fields. These two fields are } \\
\text { combined and used with context } \\
\text { awareness technology for better } \\
\text { performance. }\end{array}$ \\
\hline Localization Technology & Security Technology \\
\hline $\begin{array}{l}\text { One charming certainty of ubiquitous } \\
\text { registering is that furnishing sharp items } \\
\text { with proper transmitters and } \\
\text { beneficiaries empowers exact freedom. } \\
\text { Localization technology also use the } \\
\text { Context awareness technology for better } \\
\text { communication and results. }\end{array}$ & $\begin{array}{l}\text { The principal targets of a security } \\
\text { instrument are to guarantee classification, } \\
\text { honesty, non-renouncement, accessibility, } \\
\text { darkness and reality. For getting this goal } \\
\text { in an efficient and secure way context } \\
\text { awareness technology is used. }\end{array}$ \\
\hline Machine to Machine Communication & Human Machine Interface \\
\hline $\begin{array}{l}\text { The institutionalization of proper } \\
\text { machine-machine interfaces and their } \\
\text { advancement are in this manner } \\
\text { amazingly essential for universal } \\
\text { figuring. Setting mindfulness innovation } \\
\text { is utilized as a part of this } \\
\text { correspondence for better results. }\end{array}$ & $\begin{array}{l}\text { The sharp objects of ubiquitous figuring } \\
\text { require engineers who plan UIs that move } \\
\text { past the some time ago prevailing } \\
\text { screen/console rule. Connection } \\
\text { mindfulness innovation is utilized for } \\
\text { getting it. }\end{array}$ \\
\hline
\end{tabular}

\section{RESUlts AND Discussions}

Today, ubiquitous processing is still a fantasy of development. Wide change work will be necessary to understand most of its traits, for instance, autarkic power supply, machine-machine communication, human-machine interface and security developments. Beside RFID-based logistics and security systems, there are not a lot of unavoidable figuring applications at present in proximity. However the spread and use of the Internet and mobile phones over the earlier decade proposes how quickly ICT can make impact and even change far reaching parts of society.

In the short run, general handling is the continuation of the Internet. The development of ubiquitous preparing is encapsulated by two qualities that may appear to be contradicting at first look. On one hand, only two or three unavoidable preparing applications exist at present. On the other hand, various authorities assume that different applications will be recognized inside the accompanying one to five years. No doubt, these early sharp things will offer joining of different limits, which will consolidate, particularly, certain unmistakable capacities and data exchange by method for convenient broadband, enabling relationship with the Internet. 
International Journal of Software Engineering \& Applications (IJSEA), Vol.7, No.6, November 2016

As a sensible outcome, the main pervasive processing applications will most likely draw strongly on come again is now acknowledged in the Internet. Varying media and information correspondence will combine, existing media bursts will be defeat, and the likelihood of computerized correspondence will get to be ubiquitous. Pervasive processing offerings will be rung by means of a large number of ordinary electronic gadgets, while the administrations themselves will be given by a focal, Internet-based IT foundation. The nearby communication between web administrations and the goals of universal figuring is likewise reflected in what are required to be its initial employments. Since versatility is a focal trademark in the early phase of omnipresent processing, one can expect that empowering Internet availability from any gadget will be the principle center. Savvy items will in this manner speak to an emergence of accessible online administrations. In the coming years, omnipresent registering will be encapsulated not by the fridge or range consequently associating with formulas, yet by universal access to data and administrations accessible over the Internet. Over the extended pull, ubiquitous registering will audibly change forms in the individual, financial and open domains. In the extended pull, as universal processing is coordinated into regular items and they get to be organized, data and control frameworks that are without further ado brought together in industry, transport, the administration business and the general people part can be decentralized and facilitated. In the individual domain, ubiquitous ICT resolve convey novel capacities to regular articles and more chances to impart whenever and anyplace. To pick up a feeling of the potential and the points of confinement of immanent ubiquitous processing, its focal harbinger, the Web, can dish up as a form. Through the spread of the Internet in the public arena and the financial system, various social and monetary procedures have to be sure changed essentially or even on a very basic level. In financial terms, however, one can't talk about a simply Internet-based culture and financial system.

At a standstill, present are singular businesses that are experiencing significant alter and that end up in emergency because of digitalization and the Internet. The music and film commercial enterprises outfit the most striking case, subsequent to their items, which are as of now accessible in advanced frame at any rate (CD or DVD) can without much of a stretch be replicated to other computerized media.

In view of encounters with the Internet and its steady advancement and extension, and additionally on the attributes of omnipresent registering, one can distinguish focal fields that will shape pervasive processing later on. The frequently verifiable activities and the high level of systems administration in universal figuring make it hard to unequivocally see and control framework exercises. This makes it all the more imperative for clients to have the capacity to thoroughly believe the administrations and substance of universal figuring.

This trust involves:

- The non-reputability and correct content of services

- The safety of information in ever-present computing, and

- The watchful treatment of personal data

Usage of these benchmarks should depend similarly on mechanical, authoritative and administrative instruments.

On the innovative side, there is still an extraordinary requirement for innovative work in numerous zones. A wide range of difficulties anticipates industry, science and examination support, particularly with respect to autarkic force supply, the human-machine interface and safety advancement. 
International Journal of Software Engineering \& Applications (IJSEA), Vol.7, No.6, November 2016

The detailing and execution of specialized guidelines will apply a conclusive impact on the presentation and effect of pervasive registering. Open measures-like PC engineering in the 1980 's and the Internet in the 1990's appear to be especially appropriate to isolating the advancement of the foundation from that of the items in light of it.

This will make it conceivable to make a wide scope of openly combinable omnipresent processing items that contend exorbitantly with each other. Innovation suppliers for the pervasive processing foundation, administration suppliers, client affiliations and guidelines associations are in this way called upon to concede to suitable open gauges, keeping in mind the end goal to counter inclinations toward imposing business model.

Similar to the Internet, invasive registering is not past the law. Client recognition of a structure will depend vigorously on tenets that will promise that they can have the vital trust in its administrations and substance. These incorporate guaranteeing that business and lawful activities are legitimately authoritative, characterizing risk for administrations and broken substance that cause harms, and securing the protection of information. Despite the fact that pervasive processing does not, on a basic level, make any new prerequisites past those of other appropriated data and correspondence frameworks, its imperceptibility and omnipresence will for the most part require that current guidelines be adjusted. This is especially clear with respect to information security. It stays to be seen whether the current instruments for information assurance will demonstrate sufficient as time goes on in light of the multifaceted nature of data handling and systems administration in pervasive figuring. Here, administration suppliers must create straightforwardness components, for occurrence, so that the individual can anticipate the long haul results of tolerating or dismissing a trade of data.

Because of its useful rationale, omnipresent processing can't be limited to individual nations. Globally uniform guidelines are subsequently a key prerequisite for the across the board presentation of innovation. At present, however, extremely different administrative methodologies hinder this in such domains as purchaser law, information insurance, the right to speak freely and the press, and exclusive rights law. On top of this come exceptionally shifted ways to deal with how such guidelines ought to be executed for instance, as will ful responsibilities, declarations or laws. Globally uniform standards are critically required here, with powerful instruments for confirming and upholding consistence. Something else, certain pervasive registering administrations with particular access boundaries might be accessible or usable just in specific nations, while they are banned totally in different nations, as is presently the case in fine china with confinements on Internet get to and look equipment.

A key inquiry in building up a pervasive registering base is the manner by which to guarantee basic, financially savvy and unhampered access to administrations. This is particularly critical when positive open and business administration's are offered exclusively or if nothing else specially - by means of universal processing frameworks. This could influence acquiring ageconfined items like liquor and tobacco, for occurrence, or getting to human services administrations. Especially as to open administrations, mind must be taken that culture is not part into members and non-members in omnipresent.

Ubiquitous figuring can possibly significantly change creation and business forms. This can mean not just that procedures will turn out to be progressively decentralized and adaptable; additionally that recently accessible data will expand market straightforwardness. This would tend to support little and adaptable organizations. Then again, extensive organizations are better situated to make the significant ventures at first required for omnipresent processing and to set benchmarks for cross-organization universal figuring foundations that advantage themselves the 
International Journal of Software Engineering \& Applications (IJSEA), Vol.7, No.6, November 2016 greater part of all. Organizations, their affiliations and monetary policymakers are called upon to guarantee that the chances of ubiquitous computing are similarly unlock to all organizations. Allowing for that omnipresent registering is in its outset and the fundamental innovations are best case scenario somewhat accessible or not in the least, it is difficult to predict the greater part of its social ramifications. In any case, the mechanical vision of pervasive figuring is obviously unmistakable in its forms and its specialized execution and application inside the following ten years appears to be for the most part conceivable; this will involve principal financial difficulties, as talked about above. Unmistakably, pervasive registering is a profoundly dynamic worldview that harbors an enormous potential. The examination lies in taking after its progression mindfully, and molding it efficiently to adventure its helpful outcomes while keeping away from its possible unhelpful impacts still much as could sensibly be projected.

\section{REFERENCES}

[1] M. Weiser. 1993. Hot topics-ubiquitous computing, Computer 26 (10) 71-72.

[2] ISO, 1996. Security frameworks for open systems: Access control framework, ISO/IEC 10181-3.

[3] S. Jajodia, P. Samarati, V. Subrahmanian, E. Bertino. 1997. A unified framework for enforcing multiple access control policies, in: Proceedings of the 1997 ACM SIGMOD International Conference on Management of Data, ACM Press, pp. 474-485.

[4] R. Sandhu.1998. Role activation hierarchies, in: Third ACM Workshop on RoleBased Access Control, ACM Press, pp. 33-40.

[5] D. Goldschlag, M. Reed, P. Syverson. 1999. Onion routing for anonymous and private Internet connections, Communications of the ACM 24 (2) 39-41.

[6] E. Bertino, S. Castano, E. Ferrari, M. Mesiti. 1999. Controlled access and dissemination of XML documents, in: Proceedings of the Second International Workshop on Web Information and Data Management, ACM Press, pp. 22-27.

[7] E. Damiani, D. Sabrina, S. Paraboschi, P. Samarati. 2001. Fine grained access control for soap eservices, in: Proceedings of the Tenth International Conference on World Wide Web, ACM Press, pp. 504-513.

[8] P. Viswanathan, B. Gill, R. Campbell. 2001. Security architecture in gaia, Tech. Rep., Champaign, IL, USA.

[8] W. Edwards, M. Newman, J. Sedivy. 2001. Building the ubiquitous computing user experience, in: CHI '01: CHI '01 Extended Abstracts on Human Factors in Computing Systems, ACM Press, New York, NY, USA, pp. 501-502.

[9] J. Park, R. Sandhu. 2002. Towards usage control models: Beyond traditional access control, in: Proceedings of the Seventh ACM Symposium on Access Control Models and Technologies, ACM Press, pp. 57-64.

[10] J. Jai-muhtadi, R. Campbell, A. Kapadia, M. Mickunas, S. Yi. 2002. Routing through the mist: Privacy preserving communication in ubiquitous computing environments, in: ICDCS '02: Proceedings of the 22nd International Conference on Distributed Computing Systems, ICDCS'02, IEEE Computer Society, Washington, DC, USA, pp. 74.

[11] G. Sampemane, P. Naldurg, R. Campbell. 2002. Access control for active spaces, in: ACSAC '02: Proceedings of the 18th Annual Computer Security Applications Conference, IEEE Computer Society, Washington, DC, USA, 